\section{Can Paroxetine Increase Creatine Kinase}

\section{Dicle Yenilmez ${ }^{1}$, Murat Ilhan Atagun ${ }^{2}$, Serdar Suleyman Can ${ }^{1}$, Ali Caykoylu ${ }^{1}$}

\author{
${ }^{1}$ Ankara Ataturk Training and Education Hospital, \\ Department of Psychiatry, Ankara-Turkey \\ ${ }^{2}$ Yildirim Beyazit University, Faculty of Medicine, \\ Department of Psychiatry, Ankara-Turkey
}

Journal of Mood Disorders 2014;4(2):91

\section{Dear Editor;}

Paroxetine is one of the serotonin reuptake inhibitors used frequently in treatments of anxiety and depressive disorders. We aimed to report a case that had elevated Creatine Kinase (CK) levels during paroxetine treatment, which decreased back after discontinuation of paroxetine. This case may provide further insight on paroxetine side effects, drug interactions, and mechanism of action at intracellular level.

Since 2007, this patient, with an undifferentiated connective tissue disease, had been followed by the rheumatology outpatient unit of our hospital without any abnormalities in creatine kinase (CK) levels. The patient had major depressive episodes previously, and treated with paroxetine for 6 months. She herself had begun to take paroxetine $20 \mathrm{mg}$ /day in June 2013, because of her previous experience. Initially, in July 2013, blood CK levels of $714 \mathrm{U} / \mathrm{l}$ was observed and first suspect colchicine was discontinued. However, serum CK levels remained at 506 $\mathrm{U} / \mathrm{l}$ in August 2013. Since than, paroxetine was considered to be the reason of the increased CK. The patient was

\section{References:}

1. Santos PM, Scaini G, Rezin GT, Benedet J, Rochi N, Jeremias GC, Carvalho-Silva M, Quevedo J, Streck E. Brain creatine kinase activity is increased by chronic administration of paroxetine. Brain Res Bull 2009;80:327-30.

2. Tomimoto $\mathrm{H}$, Yamamoto $\mathrm{K}$, Homburger HA, Yanagihara $\mathrm{T}$. Immunoelectron microscopic investigation of creatine kinase BB-isoenzyme after cerebral ischemia in gerbils. Acta Neuropathol 1993;86:447-55.

3. Kato T, Kato N. Mitochondrial dysfunction in bipolar disorder. Bipolar Disord 2000;2:180-90. consulted to psychiatry outpatient unit, to cease the paroxetine. After discontinuation of paroxetine, it was observed that CK values reduced to $311 \mathrm{U} / \mathrm{l}$ in September 2013 and then $146 \mathrm{U} / \mathrm{l}$ in the next month. Due to this temporal relationship, it is possible to suggest that increase of CK levels might be related with paroxetine. It is also possible that this side effect might be due to a specific vulnerability of this patient who also has a connective tissue disease.

Normal ranges of CK are between 0-25 U/L and further analysis is required when it is higher than $150 \mathrm{U} / \mathrm{L}$. The $\mathrm{CK}$ is the enzyme of the reaction that converts creatine to create phosphocreatine. Thus, it plays an important role in high energy consuming organs, such as the brain. Decreases in CK activity leads to cell death by disturbed energy balance in the cell, and by adjusting energy metabolism, antidepressants may hinder cell death in the brain $(1,2)$. In most clinical cases, CK levels may increase due to muscle damages or heart attacks. Specific subtypes might be determined to further explore the origin of the damage. Paroxetine might affect CK indirectly through signal transduction and/or gene expression. Considering that disorder of energy metabolism may have role in depression pathophysiology $(3,4)$, increases in CK activity caused by antidepressants may give an idea about the mechanisms of effect of antidepressants (5).

\section{Murat Ilhan Atagun}

Yildirim Beyazit University, Faculty of Medicine, Department of Psychiatry, Ankara-Turkey muratilhanatagun@gmail.com

This letter was accepted for publication in April 22, 2014.
4. Fattal O, Budur K, Vaughan AJ, Franco K. Review of the literature on major mental disorders in adult patients with mitochondrial diseases. Psychosomatics 2006;47:1-7.

5. Madrigal JL, Olivenza R, Moro MA, Lizasoain I, Lorenzo P, Rodrigo J, Leza JC. Glutathione depletion, lipid peroxidation and mitochondrial dysfunction are induced by chronic stress in rat brain. Neuropsychopharmacology 2001;24:420-9. 